\title{
Special issue: Selected papers of the 31st CIRECT conference, Vienna, 2012
}

\author{
Christian Glocker • Gerhard Schwarz
}

Published online: 17 January 2014

(C) Springer Science+Business Media New York 2014

On 5-8 September 2012 the Austrian Institute of Economic Research (WIFO) had the privilege of hosting the 31st CIRET Conference in Vienna. It has been the second time that WIFO organized the CIRET Conference. In view of this event the special issue of Empirica at hand provides a selection of some of the most notable papers presented at this conference.

Since the 1950s the Centre for International Research on Economic Tendency Surveys (CIRET) promotes the exchange of experience between leading researchers in the field of Business Cycle Surveys (BCS). ${ }^{1}$ Not least through its biennial conferences CIRET has been and keeps on being a major pillar in establishing Business Cycle Surveys as an invaluable source of fast and reliable information on the state of the economy and of economic agents' expectations.

The history of Business Cycle Surveys among corporations and consumers reaches back to the 1920 s at least. ${ }^{2}$ Among the longest lived representants are so well known surveys as the Purchasing Manager Index (PMI) established in 1931, ${ }^{3}$ the Survey of Consumers introduced by the University of Michigan in 1946, ${ }^{4}$ and the ifo-Konjunkturtest launched in $1949,{ }^{5}$ to name a few. Business Cycle Surveys became increasingly popular worldwide after World War II and CIRET is a central player in this development.

\footnotetext{
1 Sometimes also referred to as Business Tendency Surveys (BTS).

2 OECD, Business Tendency Surveys, A Handbook, Organisation for Economic Co-Operation and Development (OECD), 2003, p. 8.

3 http://www.ism.ws/content.cfm?ItemNumber=10743.

${ }^{4}$ http://www.sca.isr.umich.edu/fetchdoc.php?docid=24774.

5 http://www.cesifo-group.de/de/ifoHome/facts/EBDC/Ifo-DataPool/EBDC-Ifo-Business-SurveyIndustry.html.
}

C. Glocker · G. Schwarz (

Vienna, Austria

e-mail: Gerhard.Schwarz@wifo.ac.at 
As a founding member of CIRET and looking back on six decades of conducting Business Cycle Surveys the Austrian Institute of Economic Research takes pride in the fact that the 31st CIRET Conference has been the "most international" CIRET Conference ever, gathering participants from 38 countries, and one of the most successful with respect to the number of presentations, second only to the 30th CIRET Conference held in New York in 2010.

When organizing the conference, CIRET and the Austrian Institute of Economic Research were aiming for two goals. On the one hand, the traditional mission of the CIRET Conference had to be fulfilled, i.e. showing off the latest and most advanced progresses in the field of Business Cycle Surveys and their economic and econometric use. On the other hand, options for surveys in the new field of alternative welfare measures should be highlighted. Hence, the conference's special topic: "Measurement beyond GDP-the Use of Surveys". Those two goals were represented by the two renown keynote speakers, the econometrician David F. Hendry and Bruno Frey, who pioneered happiness research and the application of economics to new areas in general.

In selecting the papers for this special issue of Empirica we-the editors of this issue-strived to provide the reader with an insight into recent developments of research on Business Cycle Surveys and similar surveys. For this purpose we chose the following papers:

In "Price competition and market transparency: evidence from a random response technique" Klaus Friesenbichler, George Clarke and Michael Wong remind us that survey questions are always answered by humans and might therefore be distorted by biases, errors and fallacies. The authors showcase an approach to identify such distortions.

Pirmin Fessler, Fabio Rumler and Gerhard Schwarz present "A micro-based noninflationary rate of capacity utilisation as a measure of inflationary pressure: evidence for Austria" which utilizes firm-level data from a Business Cycle Survey. This approach of measuring inflationary pressure performs well as a driving variable of Austrian inflation in various Phillips Curve estimations while having the advantage of employing timely available data without revisions and not implying any need for arbitrary methods or concepts.

Giancarlo Bruno ("Consumer confidence and consumption forecast: a nonparametric approach") improves the forecasting of household consumption with consumer survey data by employing a non-parametric model to overcome the weaknesses of the use of traditional linear functional forms.

In "Bayesian averaging of classical estimates in forecasting macroeconomic indicators with application of business survey data" Piotr Białowolski, Tomasz Kuszewski and Bartosz Witkowski develop a methodology for forecasting key macroeconomic indicators based on business survey data. Additionally, they examine the impact of deterministic and stochastic seasonality of the business survey time series on the outcome of the forecasting and propose an intuitive procedure for incorporating both types of seasonality into the forecasting process.

Maritta Paloviita and Matti Viren use the ECB Survey of Professional Forecasters' data to analyze "Inflation and output growth uncertainty in individual survey expectations". Their results indicate a close relation between experts' 
individual inflation uncertainty and their output growth uncertainty. Furthermore, they find evidence that inflation uncertainty has a negative impact on economic activity.

Martin Falk ("Corporate patents and knowledge sourcing from universities") uses data from a questionnaire survey of firms conducting R\&D and other innovation activities to provide empirical evidence on the link between firms' external knowledge sourcing strategies and their innovation output: buying knowledge from universities is significantly positively related to the number of patent applications, while cooperating with universities and contracting out does not have an impact.

In "Financial stress and economic activity in Germany" Björn van Roye constructs an index of financial stress which is partially based on Business Cycle Survey data and demonstrates — using a threshold vector autoregressive model — that beyond a certain threshold of this index an increase in financial stress causes economic activity to decelerate significantly, whereas if it is below this threshold, economic activity remains nearly unaffected.

We hope this special issue of Empirical will contribute to further enhance the popularity of Business Cycle Surveys among scholars and practitioners and will inspire its readers to commit further research in this highly interesting field. 